ORIGINAL ARTICLE

\title{
Self and narrative in schizophrenia: time to author a new story
}

\author{
D Roe, L Davidson
}

J Med Ethics; Medical Humanities 2005;31:89-94. doi: 10.1136/jmh.2005.000214

The prevailing, clinical view of schizophrenia, as reflected in the psychiatric literature, suggests both that people with schizophrenia have lost their sense of self and that they have a diminished capacity to create coherent narratives about their own lives. Drawing on our empirical research in the growing area of recovery, we describe not only the disruptions and discontinuities introduced by the illness and its social and personal consequences, but also the person's efforts to overcome these, to reconstruct a sense of self, to regain agency and to create a coherent life narrative. We suggest in closing that, rather than simply being a byproduct of recovery, these processes of re-authoring one's life story are actually integral components of the recovery process itself.

See end of article for authors' affiliations

Correspondence to: David Roe, PhD, Institute for Health, Health Care Policy, and Aging Research, 30 College Ave, New Brunswick NJ 08901, USA; droe@ifh.rutgers.edu

Received 9 March 2005 Accepted for publication 9 June 2005
$\mathrm{T}$ here are a couple of reasons why the topic for this article may strike some readers as curious. Given the focus of this special issue, it will not be the interest in narrative or self which will be unexpected, of course, but the notion that these concepts could have relevance within the context of a disease as disruptive and devastating as schizophrenia. While other people can write narratives about persons who have schizophrenia-like Nassar's ${ }^{1}$ recent biography of Nobel laureate John Nash-the idea that a person with schizophrenia would construct his own narrative may seem at first counterintuitive. Since it was first identified as the most severe of the mental illnesses over a century ago, schizophrenia has been described not only as a loss of sanity but also as a loss of one's sense of self at the most fundamental level of self awareness. ${ }^{23}$ The third edition of the Diagnostic and Statistical Manual of Mental Disorders of the American Psychiatric Association, for example, suggests that "the sense of self that gives the normal person a feeling of individuality, uniqueness, and self direction is frequently disturbed in schizophrenia". ${ }^{4}$ If people with schizophrenia lose this kind of sense of themselves as people, as agents of their own lives, how could they possibly author their own stories?

In addition to the concern about loss of self, the clinical literature on schizophrenia has suggested that one of the core elements of the thought disorder associated with this condition is the diminished capacity of people with schizophrenia to create coherent narratives about their lives. ${ }^{5}$ While some earlier representatives of the antipsychiatry movement suggested that this difficulty reflected fragmentation and incoherence in the person's familial environment rather than in the person, ${ }^{3}$ other more recent theoreticians-reflecting a postmodernist consciousness-have suggested that this deficit is actually more of a (potential) asset. ${ }^{6}$. In any case, regardless of the cause, even if people with schizophrenia do not entirely lose their sense of self, they would still seem to have lost the ability to compose temporally unified and coherent autobiographical accounts. ${ }^{5}$ How, then, can they even construct, not to mention use to their benefit, narratives about their illness, their impact on sense of self, and their efforts to recover?

In the following, we intend to argue that these concerns about people with schizophrenia are only relevant-to the degree that they are relevant at all-to the more acute phases and/ or severe forms of the disorder. In addition, we suggest that the emerging "recovery" paradigm in community mental health opens an exciting new window onto the rich but relatively unexplored terrain of self and life reconstruction that occurs throughout the recovery process. Despite its bleak history as a progressive, deteriorating disease, we now know that over half of those individuals meeting diagnostic criteria for schizophrenia will demonstrate significant improvement over time, many recovering fully. ${ }^{7}$ As a result of this research, we suggest that it is time to author a new story about schizophrenia; one in which recovery plays at least as prominent a role as disorder. Drawing on our own empirical research in this growing area, we describe the person's efforts to deal with the disruptions and discontinuities introduced by the illness, as well as her efforts to regain a sense of agency and a coherent life narrative in their wake. We suggest in closing that, rather than simply being a byproduct of recovery, reconstructing a sense of social agency and re-authoring one's life story should be considered key dimensions of recovery which interact with other important domains in meaningful ways.

\section{SCHIZOPHRENIA AND THE NEGATION OF NARRATIVE}

On what basis has the possibility of narrative been negated in the lives of people with schizophrenia? Schizophrenia is the medical term given by the field of psychiatry that most closely captures phenomena that otherwise would be described by the lay public as insanity or madness. Talking out loud to oneself (actually in response to hallucinated voices); holding firm to false and idiosyncratic-if not outright 
bizarre-notions; failing to attend to personal hygiene; mumbling incoherently, and being terrified by thoughts that others are trying to do one harm are among the characteristic features of this potentially devastating disease which affects one out of every 100 people. While historically there has never been a consensus on what causes this condition or where it comes from (competing explanations range from demonic possession and witchcraft to faulty parenting and biological deficits), there have been concrete effects for people who appear to have it. These have included stoning; burning at the stake; confinement in distant institutions; abandonment to the streets, and a variety of treatments such as electroconvulsive therapy and lobotomy. What all of these effects had in common was that they were based on the underlying belief that the person with schizophrenia lacks reason to such an extent that he is not even aware of his lack of reason. It has been on the basis of the perception that people with schizophrenia become totally absorbed into their illness and thus lose touch with reality, that both narrative and self have been negated, leaving behind nothing more than an "empty shell" of a person. ${ }^{8}$ Not only has this perception been shown to be false, ${ }^{9}$ it also has the effect of further abandoning the person to the illness, dismissing rather than inviting narrative.

Even if the person remains behind or beneath the illness, the reader may object, surely he or she is unaware of the illness and its effects on her life. While she may still be able to tell stories, of what value could these stories be when they emanate from within the disorder? One important way in which attitudes toward schizophrenia have differed historically from other chronic illnesses has been the belief that people with schizophrenia are not aware of the fact that they have this condition and may even lack insight into the fact that they have any difficulties at all. ${ }^{10}$ Were this true, it certainly would then be a challenge for people with schizophrenia to describe how the illness has affected their lives and sense of self, since they would be unaware of any such changes. Prior to disputing these claims, it will be useful for us to consider their source in the application, and limitations, of objective/descriptive psychiatry.

Objective/descriptive psychiatry, since publication of the third edition of the Diagnostic and Statistical Manual of Mental Disorders, ${ }^{4}$ has attempted to eschew theory and a focus on the life experiences of people with mental illness in order to classify disorders based on what can be readily observed and measured. While establishing standardised measures and operational criteria for disorders has contributed to increasing the reliability of diagnostic concepts and improving communication among researchers, limiting psychiatric knowledge to what can be objectively described and measured has also made it difficult, if not impossible, for the field to consider a range of other potentially important data. Frank and Frank ${ }^{11}$ point out-for example, that descriptive psychiatry's "atheoretical" stance actually posits a theory in itself: that the meaning people attach to their symptoms, their beliefs about and attitudes toward their illness, and their social and historical context, are all unimportant. Carrying this argument a step further, Kleinman $^{12}$ emphasises the importance of engaging in participant/observation to facilitate eliciting patients' explanatory models of illness in order to understand their own personal experiences and the social sources and consequences of those personal experiences.

Kleinman's argument, along with the more recent body of work on illness narratives, ${ }^{13}$ models, ${ }^{14}{ }^{15}$ perceptions, ${ }^{16}$ and beliefs, ${ }^{17}$ suggests that we may have overlooked an extremely important dimension of schizophrenia, which is to be found precisely in the person's experiences of the illness and its impact on his life. In suggesting that lack of awareness of illness, or "anosognosia," is a core feature of schizophrenia, objective/descriptive psychiatrists overlooked the fact that it has only been very recently that we have begun to share our growing knowledge about the illness with the people who are seeking treatment. All during the previous 150 years of confinement and community care-the period during which the presumed lack of awareness of illness became established as a core feature of schizophrenia-it seldom occurred to practitioners to tell people with schizophrenia their diagnosis or to offer them information about the nature of mental illness and its treatment. Some of those few to whom it did occur were prohibited from doing so by virtue of their (psychodynamic) training, while others who offered people this information apparently did so in secret, so that we have no way of knowing the effect of such interventions on the person's degree of insight. ${ }^{18}$ More recently, however, we have begun to provide information and education about schizophrenia and its treatment not only to people newly diagnosed with the condition, but even to people considered at risk of mental illness, and with good results. ${ }^{19}$ What these findings suggest in retrospect is that we never should have expected people to be aware of the fact that they had a mental illness when we never offered them that information in the first place. This would be similar to speculating that lack of insight is intrinsic to cancer since people do not walk into their physician's office and report that they suspect they might be growing a tumour. Without any advance education, and in the face of hundreds of years of stigma, people experiencing mental illness had little reason to guess that what was afflicting them was a psychiatric disorder.

Does this mean that everyone who now develops schizophrenia will be educated about it, accept the diagnostic label, and demonstrate adequate insight into their need for treatment? No. What it does suggest, however, is that the difficulties they may encounter in accepting this diagnosis and adhering to a prescribed treatment regimen will be more alike than different from the difficulties encountered by people with other chronic illnesses. What may be more different in the case of schizophrenia is not so much the person as our own standards for acceptance or distortion of reality. That is, we seem to have a double standard pertaining to the wide range of socially acceptable ways we have to avoid the reality of our fundamental vulnerability, fragility, and mortality. In the case of other chronic or terminal illnesses, we might refer to denial or lack of acceptance of our diagnosis or prognosis as a positive illusion. ${ }^{20}$ We may be willing to lie, deceive, or go out of our way to be elusive when interacting with a dying person. But in the case of mental illness, we insist that people accept their diagnostic labelwith the good intention of improving adherence and outcome-and view their "lack of insight" as further evidence of their condition. Such a position fails to appreciate the adaptive role played by denial in much of human experience, including in adaptation to illness.

Several recent studies have confirmed the negative relationship that may exist between the acceptance of a diagnostic label and aspects of psychosocial wellbeing and quality of life, particularly when self efficacy is low-as it often is in schizophrenia. ${ }^{21-23}$ These studies suggest that one reason people with this condition may not wish to accept or discuss their diagnosis is that to do so leaves them feeling hopeless, helpless, and demoralised. In addition, there continues to be the issue of stigma. Even if I become educated about schizophrenia and accept that I have this condition, I remain aware of the fact that most people associate it with axe murderers, serial killers, or, at best, "the mentally ill". Being aware of my condition does not therefore necessarily translate into being willing to disclose that information to others. ${ }^{24}$ 
This should not come as a surprise, considering that disclosure often leads to the painful confrontation with society's prevailing stigma, ${ }^{25}{ }^{26}$ discrimination, ${ }^{27}$ and ignorance about mental illness. The devastating stigma is often further reinforced by the media ${ }^{28}$ presenting stereotypical, usually negative, images of people with mental illness, turning them into "the lepers of the 20th century". ${ }^{29}$ No wonder "having insight" or "accepting" having a mental disorder is typically not an easy or linear process.

Where does this leave us? According to the objective/ descriptive psychiatric model of schizophrenia, lack of insight is produced by an inability of the impaired brain to process data about its own dysfunction. ${ }^{30}$ Once we accept this assumption, people are doomed to confirm their diagnosis regardless of how they react to the information they are given. If they accept the diagnosis, for instance, this constitutes their agreement, despite the fact that if they really do have the illness they are not supposed to be capable of having such awareness. Agreement also renders all of their other beliefs, ideas, and decisions suspect at best, as we still view schizophrenia as impairing their cognitive abilities and judgment. If, on the other hand, they deny the diagnosis, or refuse to accept it, this act can be used as evidence that the person lacks insight and therefore must have a mental illness. ${ }^{31}$ As a result, all of her beliefs, ideas, and decisions are similarly suspect, if not dismissed out of hand. Either way, the person is viewed as lacking the essential prerequisites for being a narrator of her own experience: awareness and insight. Should the person none the less presume to offer an alternative narrative to the biomedical one, common responses to such narratives have been, according to Estroff, to "frame them as denial, lack of insight, transference, or evidence in direct contradiction to the narrator's claim of validity" ${ }^{32}$ In the end, either way, narrative has been negated.

This position reflects the fact that objective/descriptive psychiatry has tended to equate insight with the person's ability to articulate the perspective of the clinician, even when this has not been shared with him or her directly, ${ }^{33}$ resulting in an overly narrow view of awareness. In an earlier review, ${ }^{34}$ we found-for example, that patients' and staff members' attitudes toward a wide range of treatment issues almost always diverged, irrespective of the topic, place, time, and demographic or clinical characteristics of the sample. In another study ${ }^{35}$ we compared the perspectives of people hospitalised in a psychiatric facility with those of facility staff regarding the rights of hospitalised psychiatric patients. We found prevailing disagreement when treatment compromised patients' rights, with staff consistently preferring the treatment and patients preferring their rights. ${ }^{35}$

The importance of these findings is that they demonstrate that the perceptions of a person with a mental illness may or may not be a result of his disorder, or of the degree to which he has or lacks insight, but rather may simply reflect his own personal preferences. As such, these perceptions need not be challenged or changed until they match a correct or valid perception (which could be assumed to be that of the staff) but rather may represent a personal choice of equal validity. This shift from holding up a dominant worldview to which we expect all perspectives to correspond, to acknowledging the coexistence of multiple, diverse views may be a necessary precondition for encouraging people with schizophrenia to compose and share their narratives, and for these narratives to be respected, not only as valid and useful tools for research, but as a foundation for recovery as well.

\section{NARRATIVES OF SELF AND ILLNESS}

So when offered the opportunity to compose and share their narratives, what do people with schizophrenia tell us?
Ridgway $^{36}$ analysed published first person accounts of recovery and emphasised broad common passages, including moving from despair to hope, from withdrawal to engagement, and from passive adjustment to active coping and the reclaiming of a positive sense of self, meaning, and purpose. In another study, Jacobson ${ }^{37}$ analysed narratives of recovery using a dimensional analysis and identified component processes which corresponded to four central dimensions: recognising the problem; transforming the self; reconciling with the system, and reaching out to others.

Indeed, much of existing research on this topic suggests that people struggle with accepting and incorporating their illness as only one dimension of an expanded sense of self. ${ }^{38}$ These discussions of the impact of psychiatric illness on the person's former sense of self already assume, however, that the person has been made aware of the fact that other people, particularly mental health professionals and family members, view what has been happening to them as indicative of them having a major mental illness. One of the first things people with schizophrenia tell us, however, when we ask them for stories about their illness and recovery is that they were not aware initially that what they were experiencing was in fact a mental illness. In fact, people with schizophrenia typically experience symptoms for months to years with the active illness before seeking or receiving treatment. ${ }^{19}$ As we noted above, in the absence of education or other advance preparation, most people have no basis upon which to attribute their experiences of hearing voices, having strange but persistent ideas, or having various cognitive difficulties to the onset of a mental illness. Little is known about what alternative explanations people develop in the absence of this kind of biomedical knowledge.

What we are suggesting is that people with schizophrenia still need to find a way to make sense of these anomalous experiences even when they are left up to their own devices. Contrary to the objective/descriptive approach described above, our experience suggests that people are indeed acutely aware of their increasing difficulties, it is just that they do not know how to account for them. What we have found thus far is that people eventually come up with highly individual—if not idiosyncratic - explanations based on their own prior experiences, religious and cultural affiliations, and social environments. Despite the uniquely personal nature of these explanations, several common themes have emerged. These include punishment for previous sins or transgression, as well as:

religious accounts of such things as demonic possession or visitations by God; persecutory ideas about the activities of foreign powers, aliens, or various versions of the secret police (eg, CIA or FBI agents); or more up to date beliefs about being under the influence of different forms of technology, such as computer chips implanted in the brain, infrared or ultraviolet surveillance, or electronic thought broadcasting. $^{24}$

Within a clinical context, these types of explanations are often viewed as delusional ideas that are attributable to the illness, serving simply as one of its more characteristic symptoms. From a narrative perspective, however, these accounts represent the person's active attempts to make sense of his or her experiences based on the fact that there is very little in the person's previous life that speaks directly to these concerns. ${ }^{39}$

Perhaps an example will help to illustrate the difference between these two points of view. In prior research, ${ }^{24}$ we described the case of one young man with schizophrenia who attributed his difficulties to the effects of being poisoned by 
his parents. On the surface, this would appear to be a classic example of a delusion of the persecutory type. After getting to know this young man the following story emerged, which suggested that his conclusion was based on other factors in addition to his schizophrenia. He reported that he first experienced difficulties in high school with his memory, attention, and concentration, and that this led to his grades dropping. Having been an " $\mathrm{A}$ " student, and having never experienced anything like this before, he was at a loss as to what had gone wrong. The only explanation he could think of that would account for his intellectual deterioration was that he had brain damage, but he was not born with any birth defects nor had he had any traumatic brain injuries. He had not had such difficulties all of his life, and yet nor had they come on in an abrupt or sudden fashion. They had gradually built up incrementally over the previous few years but for what reason?

It must have been due, he reasoned, to an invisible yet toxic substance that had slowly been causing him brain damage. As it turned out, he had been exposed to just such a substance several days a week for the previous two years as he walked to and from his home to his part-time job at a tyre store. His route was along a busy interstate highway where cars and trucks were emitting exhaust containing carbon monoxide, a relatively invisible yet toxic substance. Walking along the edge of the interstate for the couple of miles it took him to get to and from work must have been the cause of his loss of cognitive capacity, mediated by effects of exposure to carbon monoxide on his brain. But where did his parents fit in? And how did he come to the conclusion that they had been poisoning him?

From his perspective, it was his parents' fault that he had to walk to and from work along the interstate highway, as they had refused to allow him use of one of their cars. As a result, when he was acutely upset, he blamed them directly for his exposure to the toxic substance that had caused his incremental brain damage. What suggests that this is more than just a delusional account is that the young man was relieved to learn that his condition was not due to irreparable brain damage but to schizophrenia; a disorder for which he could receive effective treatments and from which he could recover. As his cognitive functioning improved with treatment, his concern about possible brain damage was alleviated, and his anger at his parents dissipated. ${ }^{24}$ As a result, what appeared to be his delusional ideation abated also, leaving him with a very different account of his last several years.

Adopting a narrative perspective in this way broadens our horizons concerning the range of factors that might influence a person's understanding of, and response to, the onset of a mental disorder. Working from such a position, Estroff and associates ${ }^{40}$ referred to illness/identity work as the process by which a person learns about and incorporates psychiatric explanations once he or she comes into contact with mental health care or composes counterclaims about illness and self in reaction to a biomedical explanation. In their view, this process generates two main types of talk about self and illness: normalising talk, which disputes the assignation of illness and reauthorises either the condition as commonly occurring or the person as not sick, and illness identity statements, which include self representations that incorporate illness.

Lysaker et al, $^{41}$ emphasise the importance of removing obstacles from the person's capacity for dialogue between self positions $^{13}$ to increase the complex, dynamic, and diverse internal conversations of the narrator. In other words, people can entertain more than one perspective on their experience at any given time, and some people describe their silent deliberations between opposing perspectives as a useful way of adapting to the realities of having the illness. ${ }^{42}$ Narrative can be a powerful means of stimulating and bringing to life such dialogue. In the same fashion, awareness of the barriers to forming such narratives and the effort to remove them and provide enabling conditions for their development can be crucial to recovery itself.

Building on the work of Estroff, Lysaker, and others, we employed narrative constructs in the analysis of interview data in which people recovering from a psychotic episode described the experiences of self in relation to their illness. ${ }^{35}$ Data for these studies were collected as part of the Yale Longitudinal Study ${ }^{43}{ }^{44}$ and included assessing participants who were hospitalised at one of Yale Medical School's four hospitals for a psychotic disorder. Assessments were conducted during hospitalisation, shortly after discharge, bimonthly for a year, and then every six months for an additional two years. Each assessment included the use of standard rating scales and an in depth interview that was recorded and transcribed. Different qualitative analytic strategies were used and are described in greater detail in each of the studies themselves. ${ }^{42}{ }^{44}$

In one of these studies ${ }^{42}$ we identified five distinct categories that speak to different relationships that emerge in this process. In the first category, participants separated their "healthy" self from their "ill" self. This separation occurred at the narrative level, in the story the participant told and in which she created two subjects: "myself" and "myself when I am ill". In the second category, contact replaced separation between the two selves. The healthy self remained a subject, whereas the illness became an object. In narrative terms, one can say that in this category, the "healthy" self develops from focaliser to narrator, thus increasing his responsibility for his own personal story. In the third category, there was a transformation from a one sided relationship in which the self tried to act on the illness, to a two sided one in which the object (illness) was perceived as actively trying to influence the subject as well. At this stage, the more cohesive self was a more sophisticated narrator. The self used the narrator's position to change the object, the illness, making it more tolerable, which the narrator found to be empowering and which enhanced his or her capacity to cope. In the fourth category, the narrator had even more efficacy: she not only controlled the focus of the story, or the way in which it was told and made meaningful, but rather became the protagonist or her own story-that is, had control over the events and actions of the story itself and not only about the way it was told. In the fifth category, participants reached a point at which they demonstrated a capacity to integrate self and illness. They used the flexibility of narrative, incorporated with the dimension of time, to combine the different categories into a coherent whole. Thus, as seen above, allowing for multiple truths provides a foundation for the person to construct the narrative of his illness and him self in relation to it. This ongoing negotiation is important not only to separate the person's self from the illness, but also to construct a sense of self independent of the illness, as described in the following section.

\section{THE RECONSTRUCTION OF SELF THROUGH RECOVERY NARRATIVES}

Longitudinal studies conducted over the previous 30 years have demonstrated consistently that between 45 and $65 \%$ of people who meet established criteria for having a schizophrenic illness will experience significant, if not full, recovery over time. ${ }^{7}$ Qualitative research conducted with this population suggests that an effective sense of self as a social agent and a restored life narrative are not only among the results of recovery, but also appear to play a crucial role in processes of 
recovery as well. ${ }^{24}$ In this final section, we explore how this is so.

Among the more common disruptions reported by people with schizophrenia, in addition to threats to agency and identity, are experiences of decisions and actions being generated from somewhere outside of the person's own intentions, ${ }^{45}$ a sense of the person's no longer being rooted in history, ${ }^{46}$ and a sense of being engulfed by the illness ${ }^{47}$ and trapped in "patienthood". ${ }^{48}$ According to Estroff,49 this last disruption involves a social, as well as internal, process through which a once valued person is transformed into someone who is dysfunctional and devalued, first by others and then by himself as well. As she describes: "a part time or periodically psychotic person can become a full time crazy person in identity and being". ${ }^{49}$ In this respect, she compares schizophrenia to other "I am" illnesses in which the person's identity is taken hostage by the diagnosis, and hypothesises that the personal and social loss of self is actually one key component or even cause of chronicity. ${ }^{49}$

If these are the disruptions that the illness and its social impact introduce into the person's life, it stands to reason that processes of recovery will involve compensating for, if not altogether reversing, these effects. And this is, in fact, what we found in our earlier research involving follow along, narrative interviews with people recovering from schizophrenia. In our first study-for example, we described ${ }^{44}$ a four stage process of self and identity reconstruction involving the person's: 1) discovering the possibility of a more active sense of self than that which had been taken over by the illness; 2 ) taking stock of the strengths and the weaknesses of this self and assessing possibilities for change; 3 ) putting into action some of the recently (re) discovered aspects of one's self and integrating the results of these actions into a revised sense of self, and 4) employing the enhanced sense of self to provide a refuge from the disorder, thereby creating additional resources for coping. What this research suggests is that instead of losing the capacity for narrative, people acutely or severely disabled by schizophrenia have seen their previous narrative diverted through a combination of internal and social factors to one confined largely to shame, passivity, and helplessness. What is then required is a process through which this narrative can be salvaged by identifying and integrating the remaining aspects of self which have been preserved and/or unaffected by the illness.

This process can perhaps be captured well in a vignette that comes from a recent training course in which one of us was involved. In response to the trainer's description of several principles of recovery oriented practice in mental health, a participant offered the Confucian proverb that "if you give a man a fish he will eat for a day, if you teach him to fish he will eat for a lifetime". To this, another participant responded angrily: "Yeah, that sounds great. But what if the person [with schizophrenia] doesn't have the capacity to learn to fish?!" After a short pause, a gentleman then stood up in the back row of the room, identifying himself as a person in recovery from schizophrenia. From his perspective, he offered: "There are lots of other things to do besides fish". In schizophrenia, it appears that recovery requires identifying those other things the person can still do in spite of the illness, gradually rebuilding a positive and effective sense of self based on the pleasures and satisfaction that come from exercising those aspects of self, and then using the enhanced sense of self which results as a resource in coping with, compensating for, and overcoming those aspects of the illness which remain. ${ }^{44}$

Within the context of a condition as multidimensional and complex as schizophrenia, narrative is one of the few tools available that enable the person to weave back together a sense of who she is that both incorporates and yet extends beyond who she used to be prior to illness and who she has become due to illness. As we saw above, the emerging self may contain the changes and vicissitudes associated with living with the illness while simultaneously preserving a contradictory sense of the person's former life and projected future. While accepted discourse or reason would not be able to tolerate such opposing views existing side by side, narrative is flexible enough both to survive and to contain the apparent contradictions between self and illness. Even when appearing delusional to others, such narratives can serve as an organising mechanism for the person, offering the possibilities for control, continuity, flexibility, and integration. What appears to be more important in characterising such narratives is not their content, but the opportunity they provide for the person with schizophrenia to regain ownership over his own story, and thereby his own life. In recovery narratives what appears most important is that the person becomes the protagonist, the hero, of her own story, regardless of whether or not she learns how to fish or forgoes fishing in order to engage more effectively in other activities.

\section{CONCLUSION}

Life harbours an inherent tension between our universal, innate wish for completeness, coherence, and continuity, on the one hand, and frequent confrontation with internal and external events that are experienced as fragmented, conflicting, and discontinuous, on the other. Schizophrenia, along with the social and personal meanings it often holds and their many implications, poses a major challenge to any such desire for coherence and continuity. Without minimising the suffering unique to schizophrenia, it does share some of the characteristic common to traumatic events in that it generates a major interruption in the person's life story. ${ }^{39}$ We have suggested, in contrast to the historical view of schizophrenia as a progressive disease, that this interruption does not constitute a permanent loss of self and narrative as much as a disruption from which the person often can recover. To facilitate this process, we suggest focusing on the person's active efforts to regain and strengthen an effective sense of self and coherent life narrative rather than dwelling on the fact that these have been lost to the illness.

Imagine a computer virus suddenly randomly shuffling the thousands of words we composed here to convey our ideas. This disruption would pose a significant setback to our efforts to move ahead in developing, organising, and sharing our thoughts on the topic. Although understandably annoyed, if writing this paper was really important and meaningful to us, at some point we would have no choice but to try to recall what it was that we were trying to convey and start writing again. There would be no short cut to the arduous task of gathering back together the scattered words into a new version of the article. Given that this is not a puzzle where each piece has its place, the resulting article would not and could not be the same. While we are not suggesting that the impact of a virus on a Word document is similar to the impact of schizophrenia on the life of a person, we offer this analogy to illustrate a point: life is constantly vulnerable to unwanted and unpredictable interruptions, and the effort to gather up the pieces and try to put them together again is one of the most important, adaptive, healing, and creative processes of which humans are capable. Whether fixing the engine of a car, learning to play a new piece of music, or positioning personal belongings in a new house, the sanction to rearrange, put together, improvise, try again, negotiate, and create meaning through the process is crucial. This is no less true in the case of recovery from schizophrenia.

Not only are people with schizophrenia entitled to make sense of their experiences, but this process is actually crucial to their ability to live with and recover from the disorder and 
its consequences. The process of narrating suggests there is a narrator, an active agent, a self, authoring a new story. The process of authoring the story, in turn, helps to consolidate and integrate a sense of self. The interactive process we describe, and its role in recovery, suggest that mental health services should offer the opportunities and supports needed for people to be able to find, hold onto, and reclaim their stories and their selves, and encourage them to use these as resources in overcoming and living beyond the illness.

Emphasising the importance of the person's self and narrative being at the centre of care is not obvious and nor should it be taken for granted. Traditional medical research and treatment have, in various forms and to various degrees, claimed ownership over definitions of illness and its treatment. While medicine appears to be shifting toward more consumer directed care, we remain concerned that even this concept can be used to displace narrative. For instance, psychoeducational interventions focusing on insight and adherence might lose their effectiveness to the degree that they ignore, threaten, or aim to replace the making of meaning and narrative processes. ${ }^{50}$ No matter how improved new manuals may be, in that they provide useful information rather than theories that blame, and no matter how empowering they intend to be, by viewing patients as people who can learn about and understand their condition, they cannot simply replace one story-for example, bad mothers-with another prepackaged story which fails to speak to the person's own experiences-for example, a chemical imbalance. Scientific evidence is important, but only as one source of information and one thread in the person's tapestry; a tapestry that includes many other fabrics and hues. Within this larger and more complex picture, it is the narrating self and the construction of its ongoing story that must take, and remain centre stage.

\section{ACKNOWLEDGEMENT}

The authors wish to thank Drs Barbara Felton and Abraham Rudnick for their helpful comments on an earlier draft of this paper.

\section{Authors' affiliations}

D Roe, Rutgers University, Institute for Health, Health Care Policy, and Aging Research, New Brunswick, NJ, USA

L Davidson, Department of Psychiatry, Yale University School of Medicine, New Haven CT, USA

Preparation of this manuscript was supported in part by a grant from the National Institute of Mental Health (NIMH T32MH016242) to David Roe.

\section{REFERENCES}

1 Nassar S. A beautiful mind: the life of mathematical genius and Nobel laureate John Nash. New York: Simon \& Schuster, 2001

2 Eigen M. The psychotic core. Northvale, NJ: Aronson, 1986.

3 Laing RD. The divided self. New York: Penguin, 1978.

4 American Psychiatric Association. Diagnostic and statistical manual of mental disorders [3rd ed]. Washington DC, 1980:189.

5 Chaika E, Lambe RA. Cohesion in schizophrenic narratives, revisited. J Commun Disord 1989;22:407-21.

6 Sass LA. Madness and modernism. Cambridge MA: Harvard University Press, 1994.

7 Davidson L, McGlashan TH. The varied outcomes of schizophrenia. Can J Psychiatry 1997;42:34-43.

8 Andreasen NC. The broken brain. New York: Harper \& Row, 1984.

9 Davidson L, Stayner D. Loss, loneliness, and the desire for love: perspectives on the social lives of people with schizophrenia. Psychiatr Rehabil J 1997;20:3-12.

10 Morgan KD, David A. Neurological studies of insight in patients with psychotic disorders. In: Amador X, David A, eds. Insight and psychosis. New York: Oxford University Press, 2004:177-93.

11 Frank JD, Frank JB. Persuasion and healing: a comparative study of psychotherapy. [3rd ed] Baltimore, MD: The Johns Hopkins University Press, 1993.

12 Kleinman A. Rethinking psychiatry: from cultural category to personal experience. New York: Free Press, 1988.

13 Lysaker PH, Lysaker JT. Narrative Structure in psychosis. Theory Psychol 2002; 12:207-20
14 Leventhal H, Nerenz DR, Steele DF. Illness representations and coping with health threats. In: Baum A, Singer J, eds. A handbook of psychology and health. Hillside, NJ: Erlbaum, 1984:219-52.

15 Lobban F, Barrowclough C, Jones S. A review of the role of illness models in severe mental illness. Clin Psychol Rev 2003;23:171-96.

16 Weinman J, Petrie KJ. Illness perceptions: a new paradigm for psychosomatics? J Psychosom Res 1997;42:113-16.

17 Lobban F, Barrowclough C, Jones S. The impact of beliefs about mental health problems and coping on outcome in schizophrenia. Psychol Med 2004;34:1 165-76.

18 Freud S. The wolfman and other cases [translation Adey Huish L]. London: Penguin, 2002.

19 Edwards J, McGorry PD. Implementing early intervention in psychosis. London: Martin Dunitz, 2002.

20 Taylor SE, Kemeny ME, Reed GM, et al. Psychological resources, positive illusions, and health. Am Psychol 2000;55:99-109.

21 Kravetz S, Faust M, David M. Accepting the mental illness label. Psychiatr Rehabil J 2000;23:324-32.

22 Moore O, Cassidy E, Carr A, et al. Unawareness of illness and its relationship with depression and self-deception in schizophrenia. Eur Psychiatry 1999;14:264-9.

23 O'Mahony PD. Psychiatric patient denial of mental illness as a normal process. Br J Med Psychol 1982;55:109-18.

24 Davidson L. Living outside mental illness: qualitative studies of recovery in schizophrenia. New York: New York University Press, 2003:138.

25 Link BG, Cullen FT, Struening EL, et al. A modified labeling theory approach to mental disorders: an empirical assessment. Am Sociol Rev 1989;54:400-23.

26 Link BG, Cullen FT, Frank J, et al. The social rejection of former mental patients: understanding why labels matter. Am J Sociol 1987;92:1461-1500.

27 Corrigan $\mathrm{P}$, Watson $\mathrm{AC}$, Heyrman $\mathrm{ML}$, et al. Structural stigma in state legislation. Psychiatr Serv 2005;56:557-63.

28 Corrigan P, Watson AC, Gracia G, et al. Newspaper stories as measures of structural stigma. Psychiatr Serv 2005;56:551-6.

29 Torry EF. Surviving schizophrenia: a family manual. New York: Harper \& Row, 1983.

30 Laroi F, Barr WB, Keefe RSE. The neuropsychology of insight in psychiatric and neurological disorders. In: Amador X, David A, eds. Insight and psychosis. New York: Oxford University Press, 2004:119-56.

31 Roe D, Kravetz S. Different ways of being aware of a psychiatric disability: a multifunctional narrative approach to insight into mental disorder. J Nerv Ment Dis 2003;191:417-24.

32 Estroff S. Subject/subjectivities in dispute: the poetics, politics, and performance of first-person narratives of people with schizophrenia. In: Jenkins JH, Barrett RG, eds. Schizophrenia, culture, and subjectivity. USA: Cambridge University press, 2004, 282-302 at 285.

33 Greenfeld D, Strauss JS, Bowers MB, et al. Insight and interpretation of illness in recovery from psychosis. Schizophr Bull 1989;15:245-52.

34 Roe D, Lereya J, Fennig S. Comparing patients' and staff members' attitudes: does patients' competence to disagree mean they are not competent? J Nerv Ment Dis 2001;189:307-10.

35 Roe D, Weishut DJ, Jaglom M, et al. Patients' and staff members' attitudes about the rights of hospitalized psychiatric patients. Psychiatr Serv 2002;53:87-91.

36 Ridgway P. Restoring psychiatric disability: learning from first person recovery narratives. Psychiatr Rehabil J 2001;24:335-43.

37 Jacobson N. Experiencing recovery: a dimensional analysis of recovery narratives. Psychiatr Rehabil J $2001 ; 24: 248-54$.

38 Davidson L, O'Connell M, Tondora J, et al. Recovery in serious mental illness: paradigm shift or shibboleth? In Davidson L, Harding CM, Spaniol L (eds). Recovery from severe mental illnesses: Research evidence and implications for practice. Boston, MA: Center for Psychiatric Rehabilitation of Boston University.

39 Davidson L. Story telling and schizophrenia: using narrative structure in phenomenological research. The Humanistic Psychologist 1993;21:200-20.

40 Estroff SE, Lachicotte WS, Illingworth LC, et al. Everybody's got a little mental illness: accounts of illness and self among people with severe, persistent mental illness. Med Anthropol Q 1991;5:331-69.

41 Lysaker PH, Lancaster RS, Lysaker JT. Narrative transformation as an outcome in the psychotherapy of schizophrenia. Psychol Psychother 2003;76:285-99.

42 Roe D, Ben-Yishai A. Exploring the relationship between the person and the disorder among individuals hospitalized for psychosis. Psychiatry 1999;62:370-80.

43 Strauss JS, Hafez $\mathrm{H}$, Lieberman $\mathrm{P}$, et al. The course of psychiatric disorders III: longitudinal principles. Am J Psychiatry 1985;142:289-96.

44 Davidson L, Strauss JS. Sense of self in recovery from severe mental illness. Br J Med Psychol 1992;65:131-45.

45 Carpenter WT Jr, Heinrichs DW, Wagman AM. Deficit and non-deficit forms of schizophrenia: the concept. Am J Psychiatry 1988;145:578-83.

46 Kline J, Horn D, Patterson CM. Meaning and development in the interpersonal treatment of severe psychopathology. Bull Menninger Clin 1996;60:314-30.

47 Lally SJ. Does being here mean there is something wrong with me? Schizophr Bull 1989;15:253-65.

48 Roe D. Progressing from "patienthood" to "personhood" across the multidimensional outcomes in schizophrenia and related disorders. JNMD 2001;189:691-9

49 Estroff S. Self, identity and subjective experiences of schizophrenia: in search of the subject. Schizophr Bull 1989;15:189-96.

50 Roe D, Yanos PT. Moving beyond information and towards inspiration. Behavioral Therapist (in press). 